\title{
Os Dicionários Biográficos do Movimento Operário: análise comparada de um gênero científico*
} Bruno Groppo ${ }^{1}$

\section{RESUMO}

GROPPO, B. Os dicionários biográficos do movimento operário: análise comparada de um gênero científico. A partir dos anos 1960, os estudos de biografia coletiva consagrados ao movimento operário conheceram um desenvolvimento considerável, tanto na França quanto em muitos outros países e resultaram na realização de certo número de dicionários e bases de dados biográficos. A multiplicação dessas iniciativas testemunha, assim, a difusão de uma nova sensibilidade historiográfica. A abordagem sociobiográfica, inaugurada na França pelo Maitron, contribuiu para se ultrapassar a historiografia tradicional do movimento operário, que estava focalizada nas organizações, nas ideologias e nos dirigentes. Se interessando pelo papel dos militantes "obscuros", ela permitiu, entre outras coisas, reconstruir, a partir de itinerários individuais, o perfil de diferentes gerações de militantes. O artigo apresenta um panorama dos dicionários biográficos existentes e em curso. Apresenta, igualmente, os principais trabalhos de biografia coletiva concernentes ao movimento comunista realizados após a abertura dos arquivos russos e os de vários partidos comunistas.

Palavras-chave: biografia coletiva; movimento operário; dicionários biográficos.

\section{ABSTRACT}

GROPPO, B. Labor movement biographical dictionaries: A comparative analyses of a scientific genre. From the 1960's on, studies on collective biographies focusing on the labor movement, experienced a considerable development, both in France and in many other countries, and resulted in the creation of a certain number of dictionaries and databases of biographic information. The multiplication of those initiatives, then, testifies the diffusion of a new historiographical sensibility. The sociobiographical approach, inaugurated in France by the Maitron, contributed to overcome the labor movement traditional historiography, which focused on organizations, ideologies and leaders. With its interest in the "obscure" activists, it provided, among other things, the reconstruction, taking individual trajectories as a starting point, of the profile of different generations of activists. The article displays an overview of existent biographical dictionaries. It presents, as well, the main works of collective biography related to the communist movement produced after the opening of the Russian and other communist parties' archives.

Key words: collective biography; labor movement; biographic dictionaries.

\footnotetext{
* Tradução de Marilia Mezzono. Texto original: GROPPO, Bruno. Les dictionnaires biographiques du mouvement ouvrier: analyse comparée d'un genre scientifique. Matériaux pour l'histoire de notre temps. 4-1 (nº 104-105), p. 6-15, 2011. 
A partir dos anos 1960, os estudos de biografia coletiva consagrados ao movimento operário conheceram um desenvolvimento considerável, tanto na França quanto em outros países, que culminou com a realização de vários dicionários e bases de dados biográficos. O Dictionnaire Biographique du Mouvement Ouvrier Français (DBMOF) ${ }^{1}$, também chamado Maitron - por conta do nome do historiador francês Jean Maitron, que o iniciou e dirigiu - é, sem dúvida, o exemplo mais significativo do que veio a ser um gênero científico em si e uma maneira original de abordar a história dos movimentos sociais: teve papel de precursor, tornou-se uma referência importante e uma fonte de inspiração para outros dicionários biográficos. O que se deve sublinhar, entretanto, é a amplitude do movimento que se desenha a partir dos anos 1960 e, mais ainda, na década seguinte em vários países ${ }^{1}$. Juntamente com o dicionário francês, podemos citar o dicionário britânico em dez volumes dirigido por John Saville e James Bellamy (2000) ${ }^{1}$, o dicionário italiano em cinco volumes dirigido por Franco Andreucci e Tomaso Detti (1975-1979), e ainda outros (ANTONIOLI et al., 2003-2004; GIULIANELLI et al., 2006), publicados ou em realização, em países como a Bélgica (NEUVILLE, 1995), os Países Baixos (BOB REINALDA et al., 1986-2003) ', a Espanha, os Estados Unidos (PRESS, 1976 ; FINK et al., 1974 ; FINK et al., 1984) e o Brasil'1, às vezes com a ambição de cobrir o conjunto do movimento operário europeu (LANE, 1995) ${ }^{1}$ : nasceu assim uma verdadeira "Internacional de dicionários", para retomar o título de um número especial de 1994 da revista Matériaux pour l'histoire de notre temps, dedicado a essa problemática ${ }^{1}$. Trata-se, portanto, de um fenômeno científico importante, que mobilizou e que continua envolvendo um número considerável de historiadores. Um dicionário biográfico desse tipo não é, efetivamente, a obra solitária de uma pessoa. Sua realização exige a colaboração de numerosos especialistas, que partilham não somente o interesse por esse campo de pesquisa, mas também certo número de orientações e métodos. A multiplicação de obras coletivas desse gênero testemunha, pois, a difusão de uma nova sensibilidade historiográfica. A abordagem sociobiográfica inaugurada pelo Maitron contribuiu para que se ultrapassasse a história tradicional do movimento operário, que estava focalizada nas organizações, nas ideologias e nos dirigentes. Se interessando pelo papel dos militantes "obscuros", ela permitiu reconstruir, entre outras coisas, o perfil de diferentes gerações do movimento operário, com base em itinerários individuais.

Além do mais, a abordagem sociobiográfica não ficou confinada à história operária e social, mas investiu também em outros domínios, ligados ou não ao movimento operário. É o caso, por exemplo, de vários dicionários biográficos ou enciclopédias consagrados à esquerda em seu conjunto (AGOSTI, 2000; BUHLE et al., 1998; TARCUS, 2007) ou a algumas de suas correntes, às mulheres (geralmente sub-representadas nos dicionários do movimento operário) ou a grupos particulares (por exemplo, os voluntários das Brigadas Internacionais na Guerra Civil da Espanha). Uma parte das biografias que figura nessas obras está igualmente presente nos dicionários biográficos do movimento operário, quando se trata de pessoas que militaram em vários movimentos. No que concerne particularmente às mulheres, podemos citar, entre outros, a enciclopédia dirigida por Paula Hyman e Deborah Dash (1997) sobre as mulheres judias na América, que contém também numerosas biografias de militantes do movimento operário ${ }^{2}$ e o dicionário de mulheres belgas (GUBIN et al., 2006) ou o dicionário de mulheres franco-maçons na Espanha (ALBEAR, 2007). Benjamin Stora (1985) redigiu, por sua vez, um dicionário biográfico de militantes nacionalistas argelinos. Um trabalho sociobiográfico de grande envergadura está representado pelo dicionário biográfico da emigração de pessoas de língua alemã durante a ditadura nazista, no qual figuram também numerosos militantes do movimento operário alemão e austríaco (RÖDER et al., 1980). Citarei, por fim, como exemplo da abordagem sociobiográfica aplicada a todos os outros assuntos, ainda que não se trate de um dicionário biográfico propriamente dito, o trabalho de Michael Wildt (2002) sobre os quadros do Reichssicherheitshauptamt (RSHA), o principal organismo repressivo do regime nazista de 1939 a 1945. 
Essa enumeração, ainda que bastante incompleta, mostra que a abordagem sociobiográfica se generalizou verdadeiramente durante os últimos anos, no contexto de um interesse cada vez mais profundo pelo indivíduo, pela biografia, pela micro-história e pela história da vida cotidiana. Entretanto, limitarei minha análise aos dicionários biográficos do movimento operário e àqueles concernentes ao movimento comunista, considerado como uma das correntes do movimento operário. Nesse domínio, como já indiquei, o Maitron inaugurou uma linha que foi seguida por outros dicionários: a atenção não mais se concentra exclusivamente sobre os dirigentes e as grandes personalidades do movimento operário, mas estende-se também aos militantes de base e aos responsáveis intermediários, atores menos conhecidos deste movimento ${ }^{1}$. A atenção trazida às figuras menos conhecidas é uma característica específica dos dicionários do movimento operário.

A maior parte dos dicionários adotou um marco nacional considerado como o mais apropriado para o estudo desse movimento. Isso corresponde à abordagem geralmente adotada até um período recente pela historiografia do movimento operário. Alguns escolheram um marco geográfico mais restrito, como nos casos do dicionário do movimento operário catalão (BLANC et al., 2000) ${ }^{1}$, do movimento operário escocês (KNOX, 1984) ou daquele consagrado ao movimento operário do Rio de Janeiro (BATALHA, 2009). Mais raros são os que escolhem de imediato um contexto internacional, como o já citado de Aldo Agosti, os consagrados aos quadros do Komintern, que serão tratados mais adiante, ou o dicionário dos militantes anarquistas ${ }^{1}$. A escolha de um marco nacional responde, evidentemente, a exigências práticas, mas também acarreta limitações: sobretudo, ela condiciona o olhar dirigido aos militantes, já que a natureza internacional do movimento operário, os contatos, as redes transnacionais, as influências recíprocas e as transferências culturais não receberam toda a atenção que mereceriam. A obra de Michel Cordillot, A Sociale na América (2002), que tem como subtítulo "Dicionário do movimento social francófono nos Estados Unidos" mostra, por outro lado, o interesse que há em levar em conta tais aspectos e, em particular, os ligados ao problema das migrações: um aspecto cuja importância na difusão do socialismo foi sublinhada em várias ocasiões por George Haupt (1980)ํ. Nos estudos sociobiográficos sobre o movimento operário, a França ocupa uma posição particular na medida em que, no caminho aberto pelo Maitron, também foram realizados e publicados dicionários biográficos consagrados aos movimentos operários de outros países, tanto europeus quanto extraeuropeus. Isso mostra não somente o interesse pela história desses movimentos, mas também uma tomada de consciência quanto à importância da dimensão internacional do movimento operário.

O respeito aos critérios científicos e o fato de serem coordenados e realizados por historiadores de profissão figuram entre as características fundamentais dos dicionários biográficos realizados a partir de 1960. As simpatias militantes que animavam a maior parte dos autores não deram lugar, de forma geral, a uma escritura hagiográfica ou discriminatória. Essa mudança em direção a uma história científica, bem animada por um espírito militante, se desenha a partir dos anos 1960, numa conjuntura política e intelectual particular. $O$ interesse pela abordagem sociobiográfica está ligado, em larga medida, às mudanças que se produziam naquele momento na labour history, com a passagem de uma historiografia institucional político-ideológica a uma história social e cultural de trabalhadores e do mundo do trabalho, em particular sob a influência de historiadores marxistas ingleses como Edward Thompson e Eric Hobsbawm. Acompanha essa transição uma profissionalização da disciplina, que começa a adquirir reconhecimento e legitimidade universitários. A conjuntura histórica influenciou fortemente essas transformações. Os anos 1960 e 1970 foram marcados, em numerosos países, por um interesse muito forte pela história dos trabalhadores e seus movimentos, como mostra, por exemplo, a multiplicação de publicações sobre esses temas. No plano político, enquanto a influência do stalinismo e da ortodoxia soviética se enfraquecia, uma nova esquerda aderia a uma releitura da história do movimento operário. Apesar 
da aparição de novos dogmatismos e de novas ortodoxias, um novo espaço intelectual e político se abria então e tornava possível um olhar crítico sobre o passado e o presente do movimento operário e do socialismo. Terminava o tempo das biografias "exemplares", da hagiografia, da "vida dos santos" e do proletariado. No domínio historiográfico, os partidos comunistas, desestabilizados pelos abalos da desestalinização estavam, cada vez menos, em condições de impor seu monopólio sobre a interpretação de sua própria história. No conjunto, uma época terminava e outra começava, tanto no plano político quanto na historiografia. Foi precisamente nesse contexto que vários historiadores começaram a se voltar à sociobiografia e a se engajar em empreendimentos coletivos que resultaram na realização de vários dicionários biográficos do movimento operário. Eles tomavam consciência, naquele momento, da insuficiência de instrumentos à sua disposição para o estudo da história operária e da necessidade de debruçar-se não somente sobre as grandes figuras do passado, mas também sobre os militantes "obscuros", sobre a história "de baixo". Sinal dos tempos, o Instituto Francês de História Social organizou, em 1960, um colóquio sobre "O militante operário" França, a ação de Jean Maitron foi determinante, pois conseguiu convencer e fazer historiadores de convicções políticas muito diferentes e, por vezes, opostas, trabalharem juntos numa época em que as divisões ideológicas eram ainda muito fortes. Ele foi, provavelmente, o único que, graças à sua personalidade calorosa e ao seu passado, pôde realizar esse tipo de milagre.

Os dicionários biográficos do movimento operário, desenvolvidos a partir dos anos 1960, não eram mais, em si, uma novidade absoluta. Eles tiveram alguns antecedentes na França e em outros lugares. Na França, os resumos biográficos já figuravam nos 12 volumes da Encyclopédie socialiste, syndicale et coopérative de l'Internationale ouvrière, publicada de 1912 a 1921 por Adéodat Compère-Morel e igualmente, no Grand dictionnaire socialiste do mesmo autor, publicado em 19241르 no Dictionnaire du socialisme de Charles Vérecque, publicado em 1911 e, ainda, na Encyclopédie anarchiste, publicada em 1934 sob a direção de Sébastien Faure. Tais iniciativas nasceram no seio de diferentes correntes socialistas e anarquistas da época. Sobre os Estados Unidos, podemos citar um Who is who do movimento operário, publicado em 1925, que se limitava, no entanto, às personalidades eminentes (DE LEON, 1925) ou a outro Who is who de 1946, que concernia também ao Canadá (DICKERMAN, 1946) ². É interessante notar que, no início dos anos 1930, a Internacional Operária Socialista considerava realizar um "Dicionário (Handbuch) do socialismo e do movimento operário", que deveria conter um número importante de biografias; mas o projeto teve que ser abandonado em 1933, depois da ascensão de Hitler ao poder e da destruição do movimento operário alemão. ${ }^{2}$

As obras que acabei de mencionar situam numa perspectiva muito diferente daquela do Maitron. A informação útil, bastante fragmentária, limita-se, em geral, às personalidades mais conhecidas. Em relação a essas publicações, os dicionários biográficos publicados depois dos anos 1960 inovaram verdadeiramente, colocando novas questões metodológicas e epistemológicas. O trabalho sociobiográfico esteve pontuado por colóquios e seminários, dos quais muitos foram organizados em torno do Maitron. Fora da França, podemos citar, entre outros, o seminário internacional sobre os dicionários biográficos do movimento operário, organizado em 1984, em Milão, pela Fundação Brodolini e pela Fundação Feltrinelli (GIAGNOTTI, 1988); o colóquio organizado em 2005, em Linz, pela International Conference of Labour and Social History (GROPPO, et al., 2006); o ateliê "Vidas operárias: história do trabalho e autobiografias/Working Lives: Labour History and Autobiography", ocorrido no $20^{\circ}$ Congresso Internacional de Ciências Históricas em Sidney, em 2005; o colóquio "Biographien des Arbeiterbewegung: das XX. Jahrhundert" (Biografias do movimento operário: o século XX), organizado pelo Institut für Geschichte und Biographie da FernUniversität de Hagen (Bochum, 10-11 de dezembro de 2010). 
Duas experiências de biografia coletiva, realizadas respectivamente na Alemanha e no Brasil, e bastante diferentes uma da outra, me parecem particularmente significativas. Na Alemanha Federal, a abordagem da história do movimento operário pela biografia coletiva foi desenvolvida principalmente a partir do fim dos anos 1970 pelo Zentrum für Historische Sozialforschung (Centro de pesquisa social histórica), da Universidade de Colônia, por iniciativa de Wilhelm Heinz Schröder, que se interessou especialmente pelos militantes social-democratas anteriores a 1933. Entre os trabalhos de Schröder, figura um dicionário biográfico de deputados social-democratas ao Parlamento do Reich (Reichstag) de 1898 a 1918 e, sobretudo, uma base de dados chamada BIOSOP, sobre os parlamentares social-democratas no Reichstag e nos parlamentos regionais (Landtage) de 1867 a 1933 (SCHRÖDER, 1986, 1995)1. Nos dois casos, Schröder estudou um setor bem delimitado - os parlamentares nacionais e regionais - da social-democracia, principal corrente do movimento operário alemão da época. Não se trata, pois, de um dicionário biográfico da social-democracia alemã, propriamente falando, nem do movimento operário alemão em seu conjunto, mas somente de um segmento desse conjunto. Escolhendo um corpus estritamente delimitado, Schröder pôde efetuar um recenseamento exaustivo, o que é evidentemente impossível em um dicionário biográfico geral do movimento operário. Seu trabalho esclarece o itinerário profissional e político, a formação e as características sociológicas de um conjunto de militantes e quadros pertencentes à principal corrente do movimento operário alemão. Apresentados sob a forma de fichas, os apontamentos da base BIOSOP permitem toda sorte de pesquisa cruzada.

O dicionário biográfico do movimento operário do Rio de Janeiro, dirigido por Cláudio Batalha (2009), um dos principais especialistas brasileiros da história operária, é um dicionário clássico, inspirado no Maitron, que cadastra não somente os militantes, mas também as numerosas organizações operárias que nasceram no Rio entre 1830 e 1930. O trabalho é resultado de um longo processo, iniciado nos anos 1980 em Paris, quando Cláudio Batalha, então doutorando na França, frequentava o seminário de Robert Paris na EHESS e colaborava com o projeto deste último, um dicionário biográfico do movimento operário na América Latina (PARIS, 1997). De volta ao Brasil, começou a trabalhar em um projeto de dicionário brasileiro. Em 1997, durante o Congresso Nacional da Associação Nacional de História (ANPUH), o projeto foi discutido numa reunião composta por uma dúzia de historiadores interessados. Como resultado desses debates, no estado do Rio Grande do Sul, alguns historiadores coordenados por Sílvia Petersen, começaram a construir uma base de dados biográficos dos militantes daquele estado. $\mathrm{O}$ projeto de dicionário recebeu novo impulso em 2000, graças à criação, no seio da ANPUH, de um grupo de trabalho de história social, intitulado "Mundos do Trabalho". O dicionário coordenado por Batalha é o primeiro resultado do trabalho dessa rede. Outros dicionários devem aparecer. O do estado do Rio Grande do Sul está finalizado e deve ser publicado proximamente ${ }^{2}$. Dois outros dicionários, um para o estado de Minas Gerais e outro para o estado de São Paulo ${ }^{2}$ estão em elaboração. O projeto de um dicionário brasileiro desembocou, no instante, em dicionários "regionais". Os historiadores brasileiros estimaram que fosse o caminho mais apropriado em razão da dimensão quase continental do país, que torna difícil um empreendimento sociobiográfico de envergadura nacional, mas também porque, como explica Cláudio Batalha (2005), desde o início, o movimento operário no Brasil se desenvolveu principalmente sobre a base das organizações locais, sem conseguir adquirir um caráter verdadeiramente nacional. $\mathrm{Na}$ escolha das biografias, o critério adotado foi o de uma história vista de baixo: militantes pouco conhecidos, mas que deixaram um traço na história do mundo do trabalho no Rio. Numerosos apontamentos biográficos testemunham o importante papel desempenhado, no caso do Brasil, por trabalhadores e militantes imigrados da Europa. Esse aspecto foi tema de várias monografias, em particular sobre os italianos, como a de Regina Horta Duarte (1991) sobre o anarquista italiano Avelino Foscolo, a de Carlo Romani (2002) sobre outro 
anarquista italiano, Oreste Ristori, ou ainda a de Edilene Toledo (2004) sobre os sindicalistas revolucionários italianos em São Paulo.

O projeto de um dicionário biográfico latino-americano, no qual Robert Paris trabalhou por bastante tempo, infelizmente ficou inacabado. Da mesma forma, o projeto de um dicionário biográfico do movimento operário argentino, ao qual aderiram Edgardo Bilsky e Ricardo Falcon. Por outro lado, um projeto de dicionário biográfico da esquerda na América Latina está atualmente em discussão entre historiadores de diferentes países latino-americanos (Horacio Tarcus, Olga Ulianova, Gerado Caetano, Ricardo Melagr Bao, Fernando Teixeira da Silva).

\section{Biografias coletivas de militantes e quadros comunistas: primeiros passos}

As biografias coletivas concernentes ao movimento e aos regimes comunistas apresentam algumas especificidades ligadas ao estatuto particular que tinham a biografia e a autobiografia nos partidos e nos sistemas políticos comunistas. $\mathrm{Na}$ medida em que o comunismo foi uma corrente do movimento operário e da esquerda, uma parte de seus militantes figura nos já citados dicionários biográficos do movimento operário e da esquerda. Existem, todavia, biografias coletivas que concernem especificamente aos militantes e quadros comunistas: é por eles, precisamente, que nos interessamos. Não posso abordar aqui a problemática geral da biografia e do controle biográfico no movimento e nos regimes comunistas, sobre os quais existem numerosos trabalhos de Claude Pennetier, Bernard Pudal, Brigitte Studer, Berthold Unfried (STUDER et al., 2001, 2002; PUDAL et al., 2002; UNFRIED, 2006) e outros pesquisadores (FITZPATRICK, 2002, 2005). Limito-me a lembrar da dupla natureza do comunismo no século XX: movimento político e social, por um lado, e regime político, por outro, baseado no monopólio do poder pelo partido comunista. A coexistência desses dois aspectos ao longo da história comunista do século XX coloca, do ponto de vista da biografia coletiva, vários problemas, por exemplo, o de saber se ou em que medida os burocratas no poder nos regimes comunistas devem figurar num dicionário biográfico do movimento operário. $\mathrm{Na}$ mesma ordem de ideias, os dirigentes dos sindicatos estritamente submissos ao Estado, como era o caso dos sistemas de tipo soviético, devem ser considerados da mesma forma que os representantes de sindicatos independentes? E o que devemos entender por "movimento operário" nos sistemas políticos comunistas que suprimiram a independência e a autonomia das organizações de trabalhadores?

Na União Soviética, o Dicionário enciclopédico soviético Granat publicou, de 1927 a 1929, na ocasião do décimo aniversário da Revolução de Outubro, uma série de biografias autorizadas de personalidades bolcheviques, redigidas em 1924-1925 (antes da vitória de Stalin sobre os outros concorrentes à sucessão de Lênin e antes da eliminação de toda oposição no interior do partido) (HAUPT et al., 1969 ; MOSSE, 1968). Essas biografias, como sublinhou Georges Haupt (1969, p. 19), testemunham a grande diversidade ideológica e política da velha guarda bolchevique e podem ser consideradas como o primeiro esboço de uma biografia coletiva de dirigentes do partido no poder. Na medida em que o stalinismo se consolidava, tanto na União Soviética quanto no movimento comunista, tais publicações tornaram-se impossíveis, pois no sistema stalinista os dirigentes caídos em desgraça, excluídos do partido ou diretamente atingidos pelas repressões tornavam-se "não pessoas", cujos nomes não poderiam mais ser mencionados, salvo em atos de acusação e nas sentenças de condenação emitidas pelos tribunais soviéticos na ocasião de processos políticos de grande espetáculo (em particular, os "processos de Moscou" de 1936-1938, que liquidaram a velha guarda bolchevique). A prática soviética de transformar em "não pessoas" e de destinar ao esquecimento os comunistas decaídos, dissidentes ou heréticos instalou-se também 
nos outros partidos comunistas, doravante "stalinizados", ao mesmo tempo em que outras práticas igualmente originárias da experiência soviética, como as sessões de autocrítica (PUDAL et al., 2002; UNFRIED, 2002a, 2002b, 2006), a confissão pública de "desvios" cometidos até a prática de processos políticos ${ }^{1}$.

O comunismo no poder só publicou dicionários biográficos muito tardiamente ${ }^{1}$. Redigidos por "coletivos de historiadores" dos Institutos de Marxismo-Leninismo - a instituição responsável pela história e pela memória "oficiais" nos regimes comunistas - eles obedeciam a critérios essencialmente políticos, tanto na seleção de nomes que poderiam ali figurar quanto na redação dos apontamentos. "Movimento operário" tornou-se sinônimo de "movimento comunista", mais exatamente de partido comunista e de seus precursores, já que os partidos comunistas pretendiam ser o único representante autêntico do movimento operário e do socialismo. Com base em tais critérios, foi excluída a maior parte das figuras que pertenceram a outras correntes, não comunistas, do movimento operário. A seleção de personalidades comunistas podendo figurar num dicionário oficial assim concebido, também trazia problemas, já que, nesses regimes, a "história oficial" era remanejada sem cessar de acordo com as necessidades políticas do momento: figuras célebres em um momento poderiam não mais estar na linha do partido em outro, sendo então inadmissível vê-los figurar num dicionário biográfico ao lado dos "bons" comunistas. Um dos problemas mais espinhosos, depois da denúncia dos crimes de Stalin no $20^{\circ}$ Congresso do PCUS, em 1956, era o dos numerosos comunistas estrangeiros vítimas das repressões stalinianas na União Soviética nos anos 1930. O problema referia-se particularmente ao Partido Comunista Alemão, do qual várias centenas de militantes e de quadros dirigentes haviam sido executados pela polícia soviética ou condenados ao gulag e ao Partido Comunista Polonês, do qual praticamente todos os quadros que se encontravam na União Soviética quando de sua dissolução por decisão de Stalin, foram liquidados fisicamente. Fazer figurar esses nomes num dicionário biográfico significava reconhecer que o partido comunista e a União Soviética nem sempre tinham razão. Não mencioná-los, enquanto alguns entre eles tiveram papel importante na história do partido e seguiram fielmente sua linha, também não era uma solução satisfatória. Um exemplo interessante desses dilemas é o do Biographisches Lexicon da Alemanha Oriental de 1970, que apresentava, pela primeira vez, as biografias de dez dirigentes comunistas alemães vítimas da repressão na União Soviética, afirmando que eram inocentes. Imaginamos facilmente que a inclusão desses nomes não tenha sido improvisada, mas longamente discutida anteriormente e que obteve o imprimatur do alto escalão. Porém, imediatamente após a sua publicação, o volume foi retirado de circulação e só reapareceu em algumas livrarias dez anos mais tarde (WEBER, 1989, p. 45-47) ${ }^{3}$. Enquanto o partido no poder persistia em querer exercer o monopólio da verdade histórica, redigir um dicionário biográfico permanecia um exercício politicamente perigoso e a sorte de uma obra como essa era sempre incerta.

No contexto geral do comunismo, foi sobretudo o Comintern - logo nos primeiros decênios do movimento - que focalizou a atenção dos historiadores interessados pela biografia. Uma primeira exploração de caráter científico da dimensão biográfica do Comintern foi o Biographical Dictionary of the Comintern, publicado por Branko Lazitch em colaboração com Milorad Drachkovitch em 1973, época em que os arquivos dessa organização estavam ainda rigorosamente fechados. Ali figuravam 718 biografias de quadros comunistas que desempenharam um importante papel no seio da organização (LAZITCH, et al., 1973) ${ }^{1}$. Entretanto, a abordagem sociobiográfica se afirmava progressivamente no campo científico como um método original de história social, em particular na labour history (GALLUS, 2005, p. 40-46). Uma mudança decisiva nas pesquisas sobre o comunismo se produziu com a abertura dos arquivos de Moscou e, em particular, com os do Comintern, após o fim da União Soviética em 1991. 


\section{Depois da abertura dos arquivos de Moscou}

$\mathrm{Na}$ imensa quantidade de documentos do Comintern disponibilizados a partir dos anos 1990, figurava uma fonte particularmente interessante do ponto de vista sociobiográfico: as biografias ou questionários ("anketi”) biográficos de quadros e militantes comunistas do mundo inteiro conservados nesses arquivos. Uma das particularidades do movimento comunista, a partir dos anos 1920, era a obrigação, para militantes e quadros, de redigir, à intenção do partido, breves autobiografias (chamadas "bios" no jargão do Partido Comunista Francês) ou de preencher questionários biográficos detalhados, nos quais descreviam seu itinerário político, ambiente familiar, nível de estudos e profissóes exercidas, as funções no seio do partido etc. Muitos desses documentos biográficos foram conservados nos arquivos do Comintern: tornados acessíveis em parte depois da sua abertura, constituem uma fonte extremamente preciosa para os historiadores interessados na abordagem sociobiográfica, mas também para os sociólogos e antropólogos. Antes da abertura dos arquivos, os historiadores interessados pela sociobiografia tinham à disposição três tipos de fontes: em primeiro lugar, biografias e autobiografias "oficiais" de dirigentes comunistas ${ }^{1}$, escritas numa lógica hagiográfica e de legitimação política e construção identitária; em segundo lugar, os relatos autobiográficos de ex-comunistas, que acentuam, com frequência, o registro da confissão (erros ou ilusões passadas) ou o acerto de contas com o partido e os antigos camaradas ${ }^{2}$; e enfim, os documentos conservados nos arquivos de polícia ${ }^{3}$. Mais raramente, também são reunidas biografias "atípicas", escritas numa perspectiva de historiador, como por exemplo, a biografia de Stalin escrita por Boris Souvarine (1935) ou as biografias de Trotsky e Stalin por Isaac Deutscher (DEUTSCHER, 1996a, 1996b, 1998, 1973). Faltava sempre um elemento essencial: a possibilidade de acessar diretamente os arquivos dos partidos comunistas e do Comintern. Durante muito tempo, a obsessão pelo segredo, característica do movimento comunista, e a inacessibilidade aos arquivos entravaram consideravelmente o desenvolvimento das pesquisas sobre o comunismo.

A abertura dos arquivos dos partidos comunistas nos países ex-comunistas da Europa Central e Oriental depois de 1989, porém mais ainda, a dos arquivos russos, depois do fim da União Soviética, modificaram profundamente a situação e as perspectivas das pesquisas sobre o comunismo. Pela primeira vez, os documentos internos do Comintern e de outras organizações comunistas tornavam-se acessíveis aos pesquisadores, que podiam, assim, reconstruir a história do movimento comunista apoiando-se nas fontes originais. Era o fim da prática do segredo que havia cercado, por decênios, os arquivos do comunismo e as relações dos partidos comunistas com sua própria história. As modificações sobrevindas no domínio dos arquivos na Rússia inserem-se no processo geral de abertura dos arquivos em outros países ex-comunistas da Europa Central e Oriental ${ }^{4}$. Ao mesmo tempo, vários partidos comunistas ocidentais, dos quais alguns já haviam começado a abrir parcialmente seus arquivos antes de 1989, retiravam os últimos obstáculos que entravavam o acesso aos documentos, decidindo confiar sua guarda a instituiçóes públicas (arquivos nacionais ou departamentais) ou a fundações, para que os pusessem à disposição do público. Na Alemanha, assistiu-se a uma situação paradoxal: depois da reunificação, os arquivos da ex-RDA, a começar pelo arquivo do partido comunista, tornaram-se imediatamente acessíveis até 1989, enquanto na parte ocidental permanecia em vigor o prazo de 30 anos para acessar os documentos da história contemporânea. $\mathrm{O}$ destino final dos arquivos comunistas mostrava, em todo caso, que uma página da história fora definitivamente virada.

Nãoémeu objetivoaqui esclareceras repercussões da “revoluçãodosarquivos" sobre ahistoriografiado comunismo em geral. Limitar-me-ei a levar em consideração aqueles que concernem especificamente à problemática sociobiográfica. É preciso notar, antes de tudo, que a abertura dos arquivos russos não foi completa. Certas partes, consideradas politicamente sensíveis, permaneceram fechadas: 
outras ainda, depois de terem sido abertas durante certo tempo, foram novamente fechadas em seguida. No caso dos dossiês pessoais dos militantes comunistas conservados nos arquivos do Comintern, a abertura foi apenas parcial, pois continham documentos concernentes à vida privada. Os pesquisadores puderam ter acesso a uma parte dos documentos que figuravam nesses dossiês, mais precisamente, aos questionários biográficos e autobiográficos de partido. Isso foi feito geralmente no contexto de projetos de cooperação científica entre o RGASPI (Arquivos de Estado Russos de História Social e Política) e historiadores russos, por um lado, e historiadores ocidentais, por outro. Três projetos fizeram avançar consideravelmente os conhecimentos biográficos sobre os comunistas que desempenharam um papel no seio do Comintern. O mais ambicioso foi realizado na Universidade de Hanover, sob a direção de Michael Buckmiller e Klaus Meschkat e resultou na criação de uma base de dados e na publicação de um volume intitulado "Manual [ou Dicionário] biográfico sobre a história do Comintern”. (BUCKMILLER et. al., 2007)1 Um segundo projeto, mais limitado, sobre os quadros de língua francesa do Comintern, foi realizado por uma equipe de historiadores franceses, belgas, suíços, luxemburgueses, russos (Claude Pennetier, Serge Wolikow, Michel Dreyfus, José Gotovich, Brigitte Studer, Peter Huber, Henri Wehenkel, Mikhaill Narinski), no conjunto do Centro de História e Sociologia das Esquerdas (Universidade Livre de Bruxelas), do Centro de Pesquisas de História Contemporânea (Universidade de Dijon) e do RGASPI de Moscou (GOTOVITCH et al., 2001). Uma terceira iniciativa, ligada ao projeto biográfico de Hanover, resultou em um dicionário biográfico, em espanhol, sobre o Comintern e a América Latina, redigido por dois historiadores russos, Lazar Jeifets e Victor Jeifets, e um historiador suíço, Peter Huber (JEIFETS, et al., 2004).

Os três dicionários têm em comum, antes de tudo, o objeto de estudo: o Comintern e os primeiros decênios do movimento comunista. Essa coincidência não é fruto do acaso: é, com efeito, sobre este primeiro período que os arquivos de Moscou forneceram a maior quantidade de documentos. É também o período ao longo do qual - dentro do movimento comunista e de acordo com o novo tipo de militante e quadro preconizados pelos bolcheviques - foram formados muitos dirigentes que desempenharam papéis-chave nos partidos comunistas mesmo após a dissolução do Comintern. É, enfim, o período durante o qual o comunismo apresenta mais homogeneidade. Depois de 1945, assiste-se à fragmentação do movimento, primeiro com o cisma iugoslavo e, em seguida e sobretudo, com o cisma chinês (e albanês), que o divide de maneira irreversível.

Uma segunda característica comum a essas iniciativas é o fato de terem sido realizadas em colaboração com historiadores e arquivistas russos (trabalhando no contexto do RGASPI, a instituição russa herdeira do Instituto de Marxismo-Leninismo e de seus arquivos) entre eles, os do Comintern. Tal colaboração entre especialistas ocidentais e especialistas russos, animada por preocupações científicas e não políticas era impensável no tempo da Guerra Fria e materialmente impossível antes da abertura dos arquivos.

Observaremos, enfim, que essas iniciativas coincidem em parte. Os cominternianos de língua francesa e aqueles da América Latina (ou que desempenharam um papel relacionado a esse continente) já figuram, normalmente, na base de dados de Hanover; por outro lado, cominternianos de língua francesa, como o suíço Jules Humbert-Droz, estiveram estreitamente envolvidos com as questôes da América Latina e figuram também no dicionário latino-americano.

O projeto germano-russo de Michael Buckmiller e Klaus Meschkat propôs efetuar, com base nos arquivos de Moscou e em outras fontes disponíveis, um recenseamento exaustivo dos comunistas que, de uma forma ou de outra, desempenharam um papel no Comintern. O resultado foi um conjunto de 28.626 nomes registrados e de 15.815 biografias; o mais importante, por suas dimensões, 
realizado até hoje. Entre os nomes que figuram nessa base de dados, 6.000 eram completamente desconhecidos inicialmente. Os dados não foram apresentados sob a forma de relatos biográficos, mas de fichas, todas construídas de acordo com o mesmo modelo. Cada ficha compreende seis seções, nas quais figuram diferentes tipos de informações sobre o militante em questão. Uma dessas seções indica se existe, nos arquivos de Moscou, um dossiê pessoal sobre o militante, assim como referências de documentos de arquivos utilizados. A base de dados está disponível em CD-ROM, mas não em edição de papel e somente em língua alemã. $\mathrm{O}$ volume que acompanha o CD-ROM contém os atos de um colóquio internacional ocorrido em 2004, na Universidade de Hanover, em conclusão do projeto. Inclui as comunicações apresentadas no colóquio pelos principais colaboradores alemães e russos do projeto, como também por alguns outros especialistas (José Gotovitch, Felix Tych, Hermann Weber). Esta obra é interessante tanto pelo método, pelas reflexões que propõe sobre a problemática da biografia coletiva, quanto pelas informações fornecidas pelos arquivistas russos sobre diferentes aspectos dos arquivos do Comintern. O projeto biográfico foi inspirado em trabalhos de biografia coletiva realizados na Universidade de Colônia, sob a direção do professor Schröder, em particular no BIOSOP, já citado .

O dicionário biográfico sobre o Comintern e a América Latina, publicado por Peter Huber, Lazar Jeifets e Victor Jeifets em 2004, em espanhol, foi realizado em grande parte no contexto do projeto biográfico de Hanover, no qual os autores colaboraram. Uma primeira versão apareceu em russo, em Moscou, no ano 2000, somente com a assinatura de Lazar Jeifets e Victor Jeifets, com o título "A América Latina na órbita do Comintern. Ensaio de dicionário biográfico" (JEIFETS e JEIFETS, 2000). O dicionário de 2004 compreende 900 resumos biográficos de comunistas latino-americanos ou que tiveram relação com a América Latina (como emissários do Comintern, por exemplo). Eles são apresentados como uma enumeração de dados factuais (etapas do itinerário político, funções exercidas etc.), o que torna a leitura um pouco árida. Apesar desses limites e a despeito de certos erros ou imprecisões - quase inevitáveis, aliás, neste tipo de trabalho -, a obra preenche uma lacuna e constitui um ponto de partida para pesquisas mais aprofundadas. A dimensão biográfica do comunismo na América Latina só havia sido estudada até então de maneira bastante fragmentária. A tarefa é particularmente difícil e complicada, em razão do estado lacunar da documentação existente e da situação precária dos arquivos do movimento comunista na maior parte dos países latino-americanos. Certas publicações recentes revelam-se preciosas, entretanto, para uma abordagem biográfica do comunismo latino-americano, mesmo que concernindo apenas parcialmente ao tema. É o caso, por exemplo, do dicionário biográfico da esquerda argentina, publicado em 2007 sob a direção de Horacio Tarcus (2007). Cobrindo um período de mais de um século, de 1870 a 1976, essa obra pioneira - que se inspira amplamente no Maitron - só concerne parcialmente aos comunistas, aos quais consagra, entretanto, uma centena de biografias, frequentemente muito detalhadas, em um total de 500. O interesse dessas biografias comunistas ultrapassa, aliás, o contexto argentino, pois muitas delas (por exemplo, a de Victorio Codovilla, as dos irmãos Rodolfo e Orestes Ghioldi, a de Carlos Dujovne etc.) esclarecem o funcionamento das redes comunistas ao nível da América Latina em seu conjunto, assim como as relações que existiram entre os diferentes partidos comunistas da região.

O projeto concernindo aos cominternianos de língua francesa fixou um objetivo mais limitado que o projeto de Hanover: recensear os quadros e os militantes de língua francesa que foram ativos no seio do Comintern. Visava, essencialmente, à França, à Bélgica, à Suíça e a Luxemburgo ${ }^{6}$. Também realizado com a colaboração de especialistas russos, esse projeto nasceu na esteira do Maitron, com vários de seus responsáveis há muito tempo envolvidos neste empreendimento prosopográfico. Além disso, os volumes do Maitron relativos ao período 1914-1939 concernem também ao comunismo 
como corrente do movimento operário francês ${ }^{7}$. O dicionário biográfico dos cominternianos de língua francesa nasceu de uma rede informal de pesquisadores interessados pela abordagem sociobiográfica da história do movimento operário e do comunismo que já tinham o hábito de trabalhar juntos. Franceses, belgas, suíços, luxemburgueses, tinham em comum a língua francesa, e foi principalmente essa restrição linguística que os levou também a delimitar o projeto. O grupo havia estabelecido contatos regulares com historiadores e arquivistas russos (Mikhail Narinski, Michel Panteleïev, Marina Smolina), e foi essa colaboração que originou, por fim, o dicionário. O volume se abre com um ensaio de Serge Wolikow sobre a história do Comintern e apresenta cerca de 500 biografias redigidas de acordo com o modelo daquelas do Maitron: são autênticas histórias de vida, detalhadas, solidamente documentadas e bem apresentadas ${ }^{8}$.

$\mathrm{Na}$ apresentação do que denomina "um ensaio de biografia coletiva", Claude Pennetier escreve que esta obra "permite descobrir, atrás da imagem enrijecida do cominterniano, ao mesmo tempo aventureiro e agente disciplinado, a vida dos atores [da Internacional Comunista] em seus diferentes períodos. Aos criadores, por vezes afastados pela evolução da Internacional, sucede uma geração bolchevique formada nas Escolas Leninistas, enquadrada, 'verificada', disciplinada, que forjará as direções dos partidos comunistas nacionais, não sem dificuldades, assim como exaltará o 'homem novo' (...). Os cominternianos eram, em primeiro lugar, os atores da vida de instâncias internacionais (congresso, plénum), mas também os emissários políticos e técnicos em diferentes seções ou responsáveis pelos serviços na sede do Comintern. O secundário torna-se principal. Oferecendo alguns 500 itinerários, temos vontade de permitir uma releitura da dimensão internacional do comunismo no tempo do bolchevismo e do stalinismo." (PENNETIER, 2001, p. 8).

Certos trabalhos recentes de biografia coletiva concernem mais especificamente a alguns partidos comunistas. O mais notável é, em minha opinião, o dicionário biográfico dos comunistas alemães, publicado em 2004 por Hermann Weber e Andreas Herbst, que abarca o período de 1918-1945.? Esta obra é o coroamento de uma longa série de trabalhos nos quais Hermann Weber, o principal especialista do comunismo alemão, também explorou a dimensão biográfica do movimento. Seu estudo sobre o comunismo alemão na República de Weimar, publicado em 1969, e que se tornou uma obra de referência, já continha mais de 500 biografias de quadros comunistas alemães redigidos a partir das informações então disponíveis. Essas biografias não se limitavam ao período da República de Weimar (1919-1933), mas levavam em conta igualmente a trajetória política ulterior desses quadros, durante a ditadura nacional-socialista e depois de 1945. Em 1989, Weber publicou uma obra sobre comunistas alemães vítimas das repressões stalinianas ${ }^{6}$ : ali figuravam curtas biografias de aproximadamente 400 comunistas alemães que haviam perdido a vida nas prisões ou nos campos soviéticos ou, como alguns, na Alemanha, depois de terem sido entregues pela URSS à Gestapo no período do pacto germano-soviético. A abertura dos arquivos comunistas da ex-República Democrática Alemã após a unificação e a dos arquivos do Comintern depois do fim da URSS, permitiram a Hermann Weber, com a colaboração de Andreas Herbst, ampliar e aprofundar as pesquisas biográficas sobre os comunistas alemães, chegando ao que podemos realmente chamar de uma biografia coletiva dos comunistas alemães até 1945. A obra, editada em 2004 e reeditada em 2008, contém as biografias de 1400 quadros comunistas com responsabilidades no seio do KPD e outras organizações de massa entre 1918 e 1945. Não há, que eu conheça, trabalho de amplitude comparável a essa sobre outros partidos comunistas. Citaremos, entretanto, sempre no domínio sociobiográfico, os trabalhos de Kevin Morgan $(2001,2006)$ sobre os comunistas britânicos, as pesquisas que se multiplicaram em vários países sobre os voluntários das Brigadas Internacionais na Guerra da Espanha (SKOUTELSKY, 1998 ; BILL, 1982 ; LANDAUER, 2003 ; WEHENKEL, p. 1997 ; NIC et al., 2001 ; BAUMANN, 1997) ou sobre diferentes exílios políticos ligados 
ao movimento operário etc. ${ }^{6}$ Todos esses trabalhos se desenvolveram num contexto científico e cultural favorável ao desabrochar do método sociobiográfico.

\section{NOTAS}

${ }^{1}$ Centre d'Histoire Sociale du XXe Siècle CNRS/Université de Paris I Panthéon-Sorbonne

${ }^{1}$ Dictionnaire Biographique du Mouvement Ouvrier Français (DBMOF), sob a direção de Jean Maitron e, mais tarde, de Claude Pennetier, Paris: Editions Ouvrières/Editions de l'Atelier, 1964-1997, 44 v.

${ }^{2} \mathrm{Na}$ França, paralelamente ao DBMOF, foram publicados nove volumes de um Dictionnaire biographique du mouvement ouvrier international. Pela ordem: Autriche (sob a direção de Yvon Bourdet, Georges Haupt, Félix Kreissler et Herbert Steiner, Paris: Éditions ouvrières, 1971; Grand-Bretagne (sob a direção de Joyce Bellamy, David Martin, John Saville, adaptation de François Bédarida, Paris: Éditions ouvrières, 2 volumes - 1979 e 1986); Japon (sob a direção de Shiota Shobei, Paris: Éditions ouvrières, 2 volumes - A-L, 1978 e M-Z, 1979); Chine (sob a direção de Lucien Bianco e Yves Chevrier, Paris: Éditions ouvrières e Presses de la FNSP, 1985); Alemagne (sob a direção de Jacques Droz, Paris: Éditions ouvrières, 1990); Maroc (sob a direção de Albert Ayache, Paris: Éditions de l'Atelier, 1998); Algérie: engagements sociaux et question nationale. De la colonisation à l'indépendance (sob a direção de René Gallissot, Paris: Éditions de l'Atelier, 2006). Fazem parte dessa coleção igualmente os dois volumes seguintes: Komintern, l'histoire et les hommes. Dictionnaire biographique de l'Internationale communiste en France, en Belgique, au Luxembourg, en Suisse et à Moscou: 1919-1943 (sob a direção de José Gotovitch e Mikhail Narinski. Paris: Editions de l'Atelier, 2001); La Sociale en Amérique. Dictionnaire biographique du mouvement social francophone aux États-Unis, 1848-1922 (sob a direction de Michel Cordillot. Paris: Éditions de l'Atelier, 2002). Ainda no contexto do Maitron, foram publicados um dicionário departamental (Figures militantes en Val-de-Marne 1870-1970, sob a direção de Claude Pennetier. Paris: Editions de l'Atelier, 2009) e dicionários temáticos: Gaziersélectriciens, sob a direção de Michel Dreyfus. Paris: Editions de l'Atelier, 1996; Cheminots et militants. Un siècle de syndicalisme ferroviaire, sob a direção de Marie-Louise Goergen. Paris: Éditions de l'Atelier, 2003; Cédérom Dictionnaire biographique du SGEN (1937-1968), por Madeleine Singer. Paris, Éditions de l'Atelier; Cédérom + livret: Cheminots engagés. 9500 biographies en mémoire, sob a direção de Marie-Louise Goergen. Paris: Éditions de l'Atelier, 2007.

${ }^{3} \mathrm{O}$ trabalho prossegue, desde 2000, sob a direção de uma nova equipe composta por David Howell, Neville Kirk e Keith Gildart. Três volumes suplementares foram publicados. Diferentemente do Maitron, cada volume do DLB contém biografias que vão de A a Z. Em novembro de 2001, o Dictionary of Labour Biography, em colaboração com o "Communist Party Biographical Project" da Universidade de Manchester, organizou, na Society for the Study of Labour History (Sociedade para o Estudo da História do Trabalho), uma conferência intitulada "Labouring Lives".

${ }^{4}$ O Biografisch Woordenboek van het Socialisme en de Arbeidersbeweging in Nederland (BWSA) cobre o período entre 1848-1940 contendo mais de 570 biografias e pode ser consultado online no site do Institut International d'Histoire Sociale d'Amsterdam. Um projeto visando a atualizá-lo e a completá-lo com novas biografias está atualmente em vias de realização.

${ }^{5}$ Sobre a Austrália, cf. The Biographical Register of the Australian Labour Movement, 1788-1975, que deve ser concluído em breve e publicado em papel e CD-ROM, com mais de 2.000 notas biográficas. Cf. SHIELDS, John e MOORE, Andrew "Collective Biography and Labour History: The Case of The Biographical Register of the Australian Labour Movement, 1788-1975" (History in Australian and New Zealand Business Schools: The Proceedings of the First AAHANZBS Conference, The University of Sydney, 14-15 dez. 2009 / editado por Greg Patmore).

${ }^{6} \mathrm{~A}$ obra, com 1204 páginas, contém aproximadamente 1500 biografias.

${ }^{7}$ Matériaux pour l'histoire de notre temps, n. 34, 1994. Número especial "L'Internationale des dictionnaires".

${ }^{8} \mathrm{O}$ segundo volume inclui biografias de mulheres que foram ativas no movimento operário. 


\section{GROPPO, B.}

${ }^{9}$ Percebemos que os dirigentes do movimento operário tendo desempenhado um importante papel social e/ou político em seus países figuram também nos dicionários biográficos nacionais de outros países.

${ }^{10} \mathrm{O}$ recorte inclui não somente a Catalunha espanhola, mas também Valência e Baleares.

${ }^{11}$ Dictionnaire international des militants anarchistes, disponível somente online (http://militants-anarchistes. info/).

${ }^{12}$ Ver também o número especial do Mouvement social dedicado a Georges Haupt (n. 111, abr-jun 1980).

${ }^{13}$ Publicado depois em Le Mouvement social, n. 33-34, out. 1960 - mar 1961.

${ }^{14} \mathrm{O}$ título completo é Grand dictionnaire socialiste du mouvement politique et économique national et international (Paris: Publications Sociales, 1924).

${ }^{15}$ Outra obra do mesmo tipo foi publicada em 1976 (Who's Who in Labor. 1 ed. New York: Arno Press).

${ }^{16}$ Ver o esquema da obra nos arquivos da IOS no Instituto Internacional de História Social de Amsterdam (SAI-Archiv 340 Plan 'Handbuch des Sozialismus und der Arbeiterbewegung'. 41 Bl).

${ }^{17}$ A base de dados BIOSOP pode ser consultada diretamente no site do Centro, na Universidade de Colônia (biosop. zhsf.uni-koeln.de) ou no site da Fundação Friedrich Ebert (www.fes.de/hfz/arbeiterbewegung/Members/schochr/ biosop-online).

${ }^{18}$ Informações fornecidas ao autor do artigo por Silvia Petersen e Benito Bisso Schmidt.

${ }^{19}$ Este último coordenado por Luigi Biondi.

20 "Processos de Moscou” ocorreram após 1945 em vários países comunistas da Europa Oriental (processo Rajk na Hungria, processo Kostov na Bulgária, processo Slansky na Tchecoslováquia). Tiveram seus equivalentes na França, com o "caso" Marty-Tillon, na Itália, com o caso Cucchi-Magnani.

${ }^{21}$ Ver, por exemplo, sobre a República Democrática Alemã: Institut für Marxismus-Leninismus beim ZK der SED, Geschichte der deutschen Arbeiterbewegung. Biographisches Lexikon. Dietz: Berlin, 1970; sobre a Tchecoslováquia, Prirucni Slovnik k Dejinam KSC [A Concise Dictionary of the History of the CPCS]. Praga: Nakl. politické literatury SNPL, 1964.

${ }^{22}$ Neste volume figuram também, pela primeira vez, os nomes de ex-dirigentes comunistas caídos em desgraça, como Paul Levi, Heinrich Brandler, Ruth Fischer e outros.

${ }^{23}$ Uma nova edição, revista e ampliada, foi publicada em 1986, contendo desta vez 753 biografias.

${ }^{24}$ Típica, nesse sentido, é a autobiografia do dirigente comunista francês Maurice Thorez, Fils du peuple, publicada em 1937. Ver PENNETIER, C.; PUDAL, B. « Les autobiograhies des 'fils du peuple'. De l'autobiographie édifiante à l'autobiographie auto-analytique », in: PENNETIER, C.; PUDAL, B. (dir.). Autobiographies, autocritiques,

aveux dans le monde communiste. Paris, Berlin, 2002, p. 217-246; GROPPO, Bruno. Entre autobiographie et histoire. Les récits autobiographiques de communistes italiens publiés après 1945, in: Ibid. p. 247-265.

25 As autobiografias de ex-comunistas constituem um gênero literário em si. Ver ROLOFF, Ernst-August. Ex-Kommunisten. Abtrünnige des Weltkommunismus. Ihr Leben und ihr Bruch mit der Partei in Selbstdarstellungen. Mainz, 1968; KÜHN, Hermann. Bruch mit dem Kommunismus. Über autobiographische Schriften von Ex-Kommunisten im geteilten Deutschland. Münster, 1990. 
${ }^{26}$ Por exemplo, no caso italiano, os dossiês do Casellario Politico Centrale (Arquivo Político Central, no Archivio Generale dello Stato), meticulosamente atualizados pelo regime fascista com o objetivo de vigiar e reprimir seus adversários políticos na Itália e no estrangeiro.

${ }^{27}$ Um processo complexo, pois se tratava, entre outras coisas, de definir o futuro estatuto dos arquivos dos partidos comunistas que acabavam de ser afastados do poder e, mais amplamente, de todos os arquivos dos quais eram depositários os Institutos de Marxismo-Leninismo, estes também destinados à desaparição. Na impossibilidade de poder aprofundar aqui este aspecto do problema, nos limitamos a destacar que, em geral, os arquivos dos partidos comunistas foram depositados, em modalidades diversas, nos arquivos nacionais dos seus respectivos países. Outro aspecto do problema concernia aos arquivos de diferentes polícias políticas da época comunista.

${ }^{28}$ A base de dados está em CD-ROM. O livro contém os atos de um colóquio ocorrido em 2005, na Universidade de Hanover, como conclusão do projeto de pesquisa.

${ }^{29}$ Infelizmente, a base de dados de Hanover, diferentemente do BIOSOP, não pode ser consultada online.

${ }^{30}$ Sobre a criação e o desenvolvimento desse projeto, ver GOTOVITCH, José. Zum biographischen Wörterbuch der Kommunistischen Internationale für die französischsprechenden Länder.“ In: BUCKMILLER, Michael; MESHKAT, Klaus (dir.). Biographisches Handbuch zur Geschichte der Kommunistischen Internationale. Berlin: Akademie Verlag, 2007, p. 101-110.

${ }^{31}$ DBMOF. Quatrième partie: 1914-1939. De la Première à la Seconde guerre mondiale, sob a direção de MAITRON, Jean e PENNETIER, Claude. vol. 16-43, Paris, 1981-1993. Esta quarta parte do DBMOF foi redigida antes da abertura dos arquivos de Moscou. A abertura desses arquivos permitiu, nesse ínterim, numerosas integrações, que figuram na nova edição do Maitron, em CD-ROM.

${ }^{32}$ Um CD-ROM com todas as biografias, além de certo número de biografias suplementares, acompanha o livro de WOLIKOW, Serge. L'Internationale communiste (1919-1943). Le Komintern ou le rêve déchu du parti mondial de la révolution (Paris: Editions de l'Atelier, 2010).

${ }^{33}$ Uma nova edição, ampliada e revista, foi publicada em 2008.

${ }^{34}$ WEBER, H. Weisse Flecken in der Geschichte. Die KPD-Opfer der stalinschen Säuberungen und ihre Rehabilitierung, Frankfurt am Main, ISP-Verlag., 1989. Uma nova edição, ampliada, foi publicada no ano seguinte em Berlin, pelo editor Christoph Links. En 1998, Weber dirigiu, com Ulrich Mahlert, um importante volume sobre as depurações stalinianas: ver WEBER, H.; MAHLERT, U. (dir.). Terror: Stalinistische Parteisauberungen 1936-1953. Schöningh: Paderborn, 1998 (nova edição em 2001). Sobre o destino trágico de numerosos comunistas alemães refugiados na URSS, ver igualmente MÜLLER, Reinhard. Menschenfalle Moskau. Exil und

stalinistische Verfolgung. Hamburg: Hamburger Edition HIS Verlag, 2001 (o livro também possui uma lista das vítimas e notas biográficas).

${ }^{34}$ Ver também os ensaios reunidos em GROPPO, B. e UNFRIED, B. (2006).

\section{REFERÊNCIAS}

AGOSTI, Aldo (dir.). Enciclopedia della sinistra europea nel XX secolo. Roma: Editori Riuniti, 2000.

ALBEAR, Natividad Ortiz (dir.). Mujeres masonas en España. Diccionario biográfico (18681939). Santa Cruz de Tenerife: Escuadra y Compás, 2007. 
GROPPO, B.

ANDREUCCI, Franco e DETTI, Tommaso (dir.). Il movimento operaio italiano. Dizionario biografico, 5 vol. Roma: Editori Riuniti, 1975-1979.

ANTONIOLI, Maurizio et al., Dizionario biografico degli anarchici italiani. Pisa: BFS, 20032004, 2 vol.

AYACHE, Albert ( dir.). Maroc. Paris: Éditions de l’Atelier, 1998.

BATALHA, Cláudio (dir.). Dicionário do movimento operário. Rio de Janeiro do século XIX aos anos 1920; militantes e organizações. 2. vol. São Paulo: Fundação Perseu Abramo, 2009.

C. Labour Biography and Labour Biographical Dictionaries in Brazil. Comunicação apresentada no Congresso Mundial de Ciências Históricas (Sidney, 2005).

BAUMANN, Gino Gerold. Los voluntarios latinoamericanos en la guerra civil española. San José de Costa Rica: Editorial Guayacán, 1997.

BELLAMY, Joyce ; Martin, David ; SAVILLE, Jonh ( dir.) Grand- Bretagne (adaptation de François Bédarida). Paris: Éditions ouvrières, 2 volumes - 1979 e 1986.

BIANCO, Lucien. CHEVRIER, Yves ( dir.) Chine. Paris: Éditions ouvrières e Presses de la FNSP, 1985).

BILL, Alexander. British Volunteers for Liberty: Spain 1936-1939. London, 1982.

BLANCH, Pelai Pagès e De SANS, María Teresa Martinez (coord). Diccionari biogràfic del moviment obrer als Països catalans. Barcelone: Edicions Universitat de Barcelona-Publicacions de l'Abadia de Montserrat, 2000.

BOB REINALDA (et al). Biographical Dictionary of Socialism and the Labour Movement in the Netherlands (Biografisch Woordenboek van het Socialisme en de Arbeidersbeweging in Nederland, BWSA), ed. por Bob Reinalda et al., 9 vol., 1986-2003.

BOURDET, Yvon; HAUPT, Georges; KREISSLER, Félix; STEINER, Herbert (Ed). Autriche Paris: Éditions ouvrières, 1971.

BUCKMILLER, Michael; MESHKAT, Klaus (dir.). Biographisches Handbuch zur Geschichte der Kommunistischen Internationale. Berlin: Akademie Verlag, 2007.

BUHLE, Mari Jo; BUHLE, Paul e GEORGAKAS, Dan (dir.). Encyclopedia of the American Left. 2 ed. New York: Oxford University Press, 1998.

COMPÉRE-MOREL, Adéodat. Grand dictionnaire socialiste du mouvement politique et économique national et international. Paris: Publications Sociales, 1924.

CORDILLOT, Michel (dir.) La Sociale en Amérique. Dictionnaire biographique du mouvement social francophone aux États-Unis, 1848-1922. Paris: Éditions de l’Atelier, 2002.

DEUTSCHER, Isaac. Staline, Paris, Gallimard, 1973 (1 ed.: 1949). 
Isaac. Trotsky I. Le prophète armé, 1879-1921. Paris: Éd. Omnibus, 1996 (1

ed.: 1954). , Isaac. Trotsky II. Le prophète désarmé, 1921-1929. Paris: Éd. Omnibus, 1996

(1 ed.: 1959)

(1 ed.: 1963) , Isaac. Trotsky III. Le prophète hors-la-loi, 1929-1940. Paris: Éd. 10-18, 1998

DE LEON, Solon. The American Labor: Who's Who (for the Labor Movement). New York City: Hanford Press, 1925.

DICKERMAN, Marion, ed. Who's Who in Labor; the Authorized Biographies of the Men and Women who Lead Labor in the United States and Canada and of Those Who Deal with Labor. New York: The Dryden Press, 1946.

DICTIONNAIRE INTERNACIONAL DES MILITANTS ANARCHISTES, disponível somente online (http://militants-anarchistes.info/)

DREYFUS, Michel (dir.) Gaziers-Électriciens. Paris: Editions de l’Atelier, 1996.

DROZ, Jacques ( Ed.) Alemagne. Paris: Éditions ouvrières, 1990.

DUARTE, Regina Horta. A imagem rebelde. A trajetória libertária de Avelino Foscolo. Campinas: Pontes/Editora da UNICAMP, 1991.

ENCICLOPÉDIA GRANAT, Deiateli SSSR y Oktiabr’skoi Revoliutsii. Moscou, 1927-1929.

FINK, Gary M. et al. (eds). Biographical Dictionary of American Labor Leaders. Westport, CT: Greenwood Press, 1974.

Greenwood Press, 1984.

,Gary M. (ed.). Biographical Dictionary of American Labor. Westport, CT:

FITZPATRICK, Sheila. Le stalinisme au quotidien. La Russie soviétique dans les années 30. Paris: Flammarion, 2002.

,Sheila. Tear Off The Masks!: Identity and Imposture in Twentieth-Century Russia. Princeton: Princeton University Press, 2005.

GALLISSOT, René (dir.). Algérie. engagements sociaux et question nationale. De la colonisation à l'indépendance. Paris: Éditions de l'Atelier, 2006).

GALLUS, Alexander. "Biographie und Zeitgeschichte”. Aus Politik und Zeitgeschichte. Bonn: 2005, n. 1-2, p. 40-46.

GIAGNOTTI, Felicia (dir.). Storie individuali e movimenti collettivi. I dizionari biografici del movimento operaio. Milano: Angeli, 1988. 
GROPPO, B.

GIULIANELLI, Roberto e PAPINI, Massimo (dir.). Dizionario biografico del movimento sindacale nelle Marche (1900-1970). Roma: Ediesse, 2006.

GOERGEM, Marie-Louise (dir.). CÉDÉROM + livret: Cheminots engagés. 9500 biographies en mémoire. Paris: Éditions de l'Atelier, 2007.

, Marie-Louise (dir.). Cheminots et Militants. Un siècle de syndicalisme ferroviaire. Paris: Éditions de l'Atelier, 2003.

GOTOVITCH, José. Zum biographischen Wörterbuch der Kommunistischen Internationale für die französischsprechenden Länder. In: BUCKMILLER, Michael; MESHKAT, Klaus (dir.). Biographisches Handbuch zur Geschichte der Kommunistischen Internationale. Berlin: Akademie Verlag, 2007, p. 101-110.

GROPPO, Bruno. Entre autobiographie et histoire. Les récits autobiographiques de communistes italiens publiés après 1945, In: PUDAL, Bernard e PENNETIER, Claude (dir.). Autobiographies, autocritiques, aveux dans le monde communiste. Paris, Berlin, 2002.

Bruno e UNFRIED, Berthold (dir.). Gesichter in der Menge. Kollektivbiographische Forschungen zur Geschichte der Arbeiterbewegung/Mouvement ouvrier, biographie collective, prosopographie. Viena: Akademische Verlagsanstalt, 2006.

GUBIN, Eliane ; JACQUES, Catherine ; PIETTE, Valérie ; PUISANT, Jean (dir.) Dictionnaire Des Femmes Belges, XIX e et XX (com a colaboração de Marie-Sylvie Dupont-Bouchat e JeanPierre Nandrin). Bruxelas: Racine, 2006.

HAUPT, Georges. L'historien et le mouvement social. Paris: La Découverte, 1980.

1969. , G ; MARIE, Jean-Jacques. Les Bolchéviks par eux-mêmes. Paris: Maspero,

HYMAN, Paula E. e MOORE, Deborah Dash (ed.). Jewish Women in America: An Historical Encyclopedia. 2 vols. New York: Routledge, 1997.

JEIFETS, L., JEIFETS, F., HUBER, P. La International comunista y America Latina, 19191943. Diccionario biográfico, Moscou/Genebra: Instituto de Latinoamérica de la Academia de las Ciencias/Institut pour l'histoire du communisme, 2004.

JEIFETS, Lazar;JEIFETS, Victor.Latinskaia Amerikav orbite Kominterna, Opyt biograficheskogo slovaria. Moscou, 2000.

KNOX, William (ed.). Scottish Labour Leaders, 1918-39: A Biographical Dictionary. Edinburgh: Mainstream Publishing, 1984.

KÜHN, Hermann. Bruch mit dem Kommunismus. Über autobiographische Schriften von ExKommunisten im geteilten Deutschland. Münster, 1990. 
LANDAUER, Hans (in Zusammenarbeit mit Erich Hack). Lexikon der österreichischen Spanienkämpfer 1936-1939, Wien, 2003.

LANE, Thomas (ed.). Biographical Dictionary of European Labor Leaders, 2 vol. Westport (Connecticut): Greenwood Press, 1995.

LAZITCH, Branko; DRACHKOVITCH, Milorad. Biographical Dictionary of the

Comintern. Stanford: Hoover Institution Press, 1973.

MAITRON, Jean ; PENNETIER, Claude (dir.) Dictionnaire biographique du mouvement ouvrier français. (DBMOF). Paris: Editions Ouvrières/Editions de l'Atelier, 1964-1997, 44 v.

MORGAN, Kevin e CAMPBELl, Allan (ed.). Party People. Communist Lives. London: Lawrence \& Wishart, 2001.

MORGAN, Kevin; COHEN, Gidon; FLYNN, Andrew. Communists in British Society 19211991. London: Rivers Oram Press, 2006.

MOSSE, Werner. Makers of the Soviet Union. Slavonic and East European Review. London, n. 46, 1968, p. 141-154.

MÜLLER, Reinhard. Menschenfalle Moskau. Exil und stalinistische Verfolgung. Hamburg: Hamburger Edition HIS Verlag, 2001.

NEUVILLE, Jean (dir). Dictionnaire biographique des militants du mouvement ouvrier en Belgique. Tomo 1: A-B. Bruxelas: Editions Vie Ouvrière, 1995 (Coleção "Histoire du mouvement ouvrier en Belgique", dirigida por Jean Neuville).

NIC, Ulmi e HUBER, Peter. Les combattants suisses en Espagne républicaine (1936-1939). Lausanne: Verlag Antipodes, 2001.

PARIS, Robert. Biografias e 'perfil' do movimento operário. Algumas reflexões em torno de um dicionário. Revista Brasileira de História. Número especial “Biografia, biografias". vol. 17, n. 33, 1997, p. 9-31.

PENNETIER, Claude (dir.) Figures militantes en Val-de-Marne 1870-1970, Paris: Editions de l'Atelier, 2009.

PENNETIER, C. Présentation. In: Komintern, l'histoire et les hommes. Dictionnaire biographique de l'Internationale communiste en France, en Belgique, au Luxembourg, en Suisse et à Moscou: 1919-1943 (sob a direção de José Gotovitch e Mikhail Narinski. Paris: Editions de l'Atelier, 2001).

PRIRUCNI SLOVNIK K DEJINAM KSC [A Concise Dictionary of the History of the CPCS]. Praga: Nakl. politické literatury SNPL, 1964.

PUDAL, Bernard e PENNETIER, Claude (dir.). Autobiographies, autocritiques, aveux dans le monde communiste. Paris, Berlin, 2002. 
GROPPO, B.

RÖDER, Werner; STRAUSS, Herbert A. (dir.). Biographisches Handbuch der deutschsprachigen Emigration nach 1933-1945 / International Biographical Dictionary of Central European Emigrés 1933-1945. Munique - N. York - London - Paris: K.G. Saur, 1980.

ROLOFF (1968), Ernst-August. Ex-Kommunisten. Abtrünnige des Weltkommunismus. Ihr Leben und ihr Bruch mit der Partei in Selbstdarstellungen. Mainz, 1968.

ROMANI, Carlo. Oreste Ristori: uma aventura anarquista. São Paulo: FAPESP/Annablume, 2002.

SAVILLE, John e BELLAMY, James (ed.). Dictionary of Labour Biography, London, MacMillan, 1971-2000, 10 vol.

SCHRÖDER, Wilhelm. Heinz. Sozialdemokratische Parlamentarier in den deutschen Reichs- und Landtagen 1867-1933. Düsseldorf, 1995.

SCHRÖDER, Wilhelm Heinz. Sozialdemokratische Reichstagsabgeordnete und Reichstagskandidates 1898-1918. Biographisch-statistisches Handbuch, Düsseldorf, 1986.

SINGER, MADELEINE. CÉDÉROM Dictionnaire biographique du SGEN (1937-1968). Paris, Éditions de l'Atelier.

SHOBEI, Shiota (dir.) Japon. Paris: Éditions ouvrières, 2 volumes - A-L, 1978 e M-Z, 1979).

SOUVARINE, Boris. Staline. Aperçu historique du bolchevisme. Paris: Plon, 1935.

STUDER, Brigitte; UNFRIED, Berthold. Der stalinistische Parteikader, Köln/Wien, Böhlau, 2001.

STUDER, Brigitte; UNFRIED, Berthold; HERRMANN, Irène (dir.). Parler de soi sous Staline. La construction identitaire dans le communisme des années Trente. Paris: Editions de la MSH, 2002.

TARCUS, Horacio (dir.). Diccionario biografico de la izquierda argentina. De los anarquistas a la "nueva izquierda". Buenos Aires: Emecé, 2007.

TOLEDO, Edilene. Travessias revolucionárias: ideias e militantes sindicalistas em São Paulo e na Itália (1890-1945). Campinas: Editora da UNICAMP, 2004.

UNFRIED, B. "Ich bekenne": katholische Beichte und sowjetische Selbstkritik. Frankfurt: M. Campus, 2006.

UNFRIED, B. L'autocritique dans les milieux cominterniens des années 1930. In :PUDAL, Bernard e PENNETIER, Claude (dir.). Autobiographies, autocritiques, aveux dans le monde communiste. Paris, Berlin, 2002., p. 43-62. 
UNFRIED, B Parler de soi au parti. L'autocritique dans les milieux du Komintern en URSS dans les années trente. In: STUDER, B ; UNFRIED, B; HERRMANN, I. (dir.). Parler de soi sous Staline, sgg La construction identitaire dans le communisme des années Trente. Paris: Editions de la MSH, 2002.

SHIELDS, John e MOORE, Andrew "Collective Biography and Labour History: The Case of The Biographical Register of the Australian Labour Movement, 1788-1975” (History in Australian and New Zealand Business Schools: The Proceedings of the First AAHANZBS Conference, The University of Sydney, 14-15 dez. 2009 / editado por Greg Patmore).

SKOUTELSKY, Rémy. L'espoir guidait leurs pas. Les volontaires français dans les brigades internationales 1936-1939. Paris: Grasset, 1998.

STORA, Benjamin. Dictionnaire biographique de militants nationalistes algériens, 19261954. Paris: L'Harmattan, 1985.

WEBER, H., HERBST, A. Deutsche Kommunisten. Biographisches Handbuch 1918 bis 1945. Berlin: Dietz, 2004.

,H. Die Wandlung des deutschen Kommunismus; die Stalinisierung der KPD in der Weimarer Republik. Frankfurt am Main: Europaische Verlagsanstalt, 1969, 2 vol.

H.; MAHLERT, U. (dir.). Terror: Stalinistische Parteisauberungen 19361953. Schöningh: Paderborn, 1998 (nova edição em 2001).

H. Weisse Flecken in der Geschichte. Die KPD-Opfer der stalinschen Säuberungen und ihre Rehabilitierung, Frankfurt am Main, ISP-Verlag., 1989.

WEHENKEL, Henri. D'Spaniekämpfer. Volontaires de la guerre d'Espagne partis du Luxembourg, Dudelange, 1997.

WILDT, Michael. Generation des Unbedingten. Das Führungskorps des Reichssicherheitshauptamtes. Hamburg: Hamburger Edition, 2002.

WOLIKOW, Serge. L'Internationale communiste (1919-1943). Le Komintern ou le rêve déchu du parti mondial de la révolution (Paris: Editions de l'Atelier, 2010). 